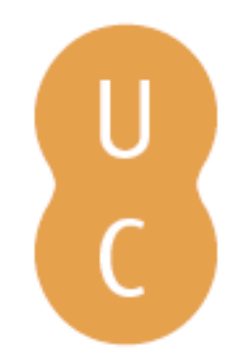

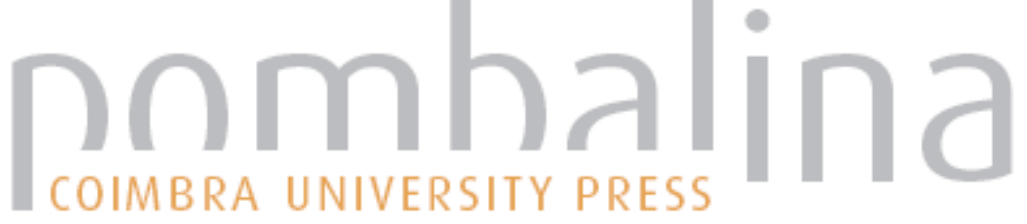

\section{Measurement of three-dimensional flow speed and direction in wildfires}

Autor(es): $\quad$ Grumstrup, Torben P.; Forthofer, Jason M.; Finney, Mark A.

Publicado por: Imprensa da Universidade de Coimbra

URL

persistente: URI:http://hdl.handle.net/10316.2/44577

DOI: $\quad$ DOI:https://doi.org/10.14195/978-989-26-16-506_60

Accessed : $\quad$ 26-Apr-2023 11:49:48

A navegação consulta e descarregamento dos títulos inseridos nas Bibliotecas Digitais UC Digitalis, UC Pombalina e UC Impactum, pressupõem a aceitação plena e sem reservas dos Termos e Condições de Uso destas Bibliotecas Digitais, disponíveis em https://digitalis.uc.pt/pt-pt/termos.

Conforme exposto nos referidos Termos e Condições de Uso, o descarregamento de títulos de acesso restrito requer uma licença válida de autorização devendo o utilizador aceder ao(s) documento(s) a partir de um endereço de IP da instituição detentora da supramencionada licença.

Ao utilizador é apenas permitido o descarregamento para uso pessoal, pelo que o emprego do(s) título(s) descarregado(s) para outro fim, designadamente comercial, carece de autorização do respetivo autor ou editor da obra.

Na medida em que todas as obras da UC Digitalis se encontram protegidas pelo Código do Direito de Autor e Direitos Conexos e demais legislação aplicável, toda a cópia, parcial ou total, deste documento, nos casos em que é legalmente admitida, deverá conter ou fazer-se acompanhar por este aviso. 


\section{ADVANCES IN}

\section{FOREST FIRE RESEARCH}

\section{8}

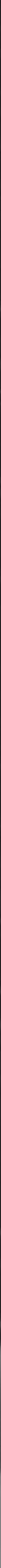




\title{
Measurement of three-dimensional flow speed and direction in wildfires
}

\author{
Torben P. Grumstrup*, Jason M. Forthofer, Mark A. Finney \\ Missoula Fire Sciences Laboratory, U. S. Forest Service. Missoula, Montana, U. S. A. \\ \{tgrumstrup@fs.fed.us*\}
}

\begin{abstract}
We report on the ongoing development of a new style of instrument package to measure three-dimensional flow speed and direction in wildland fires. The all-metal construction and lack of moving parts enables the instrument to survive immersion in flames for measurements in all fuel types. Disk style probes are used instead of the more common bi-directional probe to improve angle sensitivity of pressure measurement. Improved angular discrimination will permit calculation of fully three dimensional flow direction in addition to flow speed. An instrument package incorporating the disk anemometry system was developed and underwent preliminary testing. While the disk-style probe shows some improvement in angular sensitivity over a bi-directional probe, further improvement will result in greater tolerance in small inaccuracies in pressure measurement.
\end{abstract}

Keywords: convective heat transfer, instrumentation, wind speed, wind direction, flow velocity

\section{Introduction}

Convective heating of unburned fuel by adjacent flames has been shown to be a critical factor in the spread rate of wildfires (Finney et al. 2013; Finney et al. 2015). Calculation of the rate of heating of a given fuel element of a given shape requires knowledge of the fluid flow field (speed and direction) and temperature. For example, consider a fine fuel element like a pine needle or a small twig, which can be modeled as a cylinder. The convective heat transfer coefficient, $h$, can be determined using $h=k \cdot \mathrm{Nu} \cdot l^{-1}$, where $k$ is thermal conductivity, $l$ is a characteristic length scale (in this case, the diameter of the fuel element), and $\mathrm{Nu}$ is the Nusselt number from whose definition $\left(\mathrm{Nu} \equiv h l k^{-1}\right)$ we obtained the above relation. The Nussel number is estimated using empirical relations specific to convective heating of cylinders (e.g., see chapter 6 of (Holman 1997)). Having calculated $h$ for the fuel element, the rate of convective heat transfer per unit area is determined simply by applying Newton's law of cooling: $\dot{q}^{\prime \prime}=h\left(T_{s}-T_{\infty}\right)$ where $T_{s}$ and $T_{\infty}$ are surface temperature (of the fuel element) and ambient temperature, respectively.

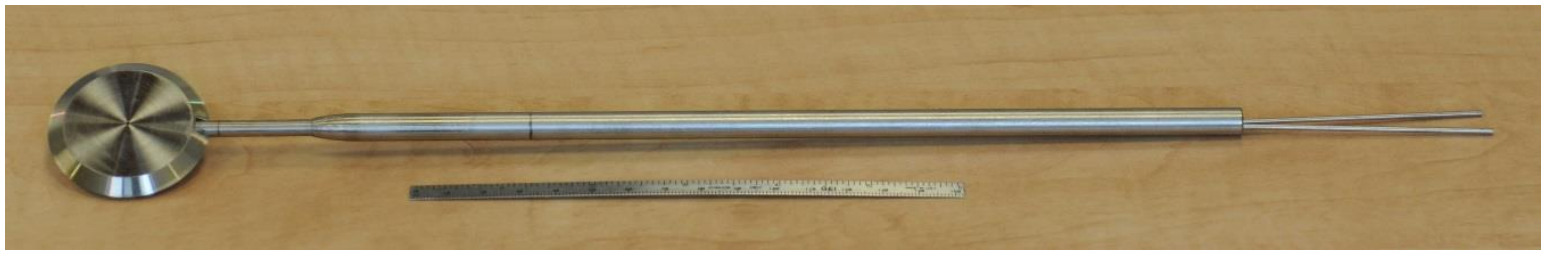

Figure 1 - A disk assembly (prior to support tube bending) showing the disk on the left, support tubing (center), and pressure tap tubes extending to the right. All materials are 304 stainless steel. A 150 mm straightedge is shown for scale.

In the course of calculating the rate of convective heating in a fire of fine fuel particles like grass, conifer needles, and small twigs, the calculations described above are simple enough. However, measurement of the flowfield velocity components and temperature in a wildland fire are more 
challenging. Instruments must be robust because they are subjected to intense heat, soot, and flying debris created by the passing fire front. They must also be rugged to withstand rough handling during transportation and deployment. Temperature measurement is easily implemented with fine-gauge thermocouples, but determination of flow speed and direction are more challenging. The meteorology research community depends on vane-and-cup and sonic anemometers for measurement of wind speed and direction. Unfortunately, they are unsuitable for fire applications because of the use of moving parts in the case of the former, and heat-sensitive electronic components in the latter. The wildland fire community needs a probe that is free of moving parts and has no exposed electronics (and, hopefully, inexpensive as well).

The bi-directional pressure probe has been a mainstay of velocity measurement in structural fire and wildfire research since it was introduced by McCaffrey and Heskestad in 1976 (McCaffrey and Heskestad 1976). While unarguably suitable for flow speed measurement, the bi-directional probe is (by design) markedly insensitive to the angle of the probe axis to the flow, making it unsuitable for determining three-dimensional flow direction. Motivated by a need to measure convective heating very near a spreading fire front, we are in the process of adapting a new type of probe that possesses the speed measurement capability of a bi-directional probe, but with improved sensitivity to angle: the disk anemometer (see Fig. 1).

The disk anemometer, like the bi-directional probe, is a differential pressure anemometer. That is, flow velocity is determined by measuring the difference in pressure between the side facing the flow and the side facing away from the flow. When three orthogonally oriented probes are used, a previously-determined calibration curve is consulted and, through a short series of iterations where Reynolds number is initially guessed then refined, flow speed and direction is determined (Green $e t$ al. 2001). The disk geometry and beveled edges make the pressure differential more strongly a function of flow angle.

The disk anemometer was invented by researchers from the University of British Columbia (Green and Rogak 1999; Green et al. 2001) who were working to develop a low cost 3D anemometer for maritime and other harsh meteorological environments. We adapted their disk anemometer concept into our heat flux instrument packages, which are fireproof and field-deployable (Fig. 2a). All components external to the electronics enclosure are stainless steel. The electronics enclosure is aluminum for light weight and can be insulated to the extent required for any given fuel type. Each disk contains a pressure tap on either face. Small stainless steel tubes communicate pressure from each tap down through the support tubes and into the electronics enclosure. There pressure is measured by differential pressure transducers (Fig. 2b) for the three disks respectively. Gas temperature is measured by a pair of fine gauge Type $\mathrm{K}$ thermocouples and radiation by a radiant heat flux gauge. Data from the three pressure transducers, two thermocouples, and the heat flux gauge are acquired by a dedicated in-house-designed logger, which also resides in the enclosure (Fig. 2c). 


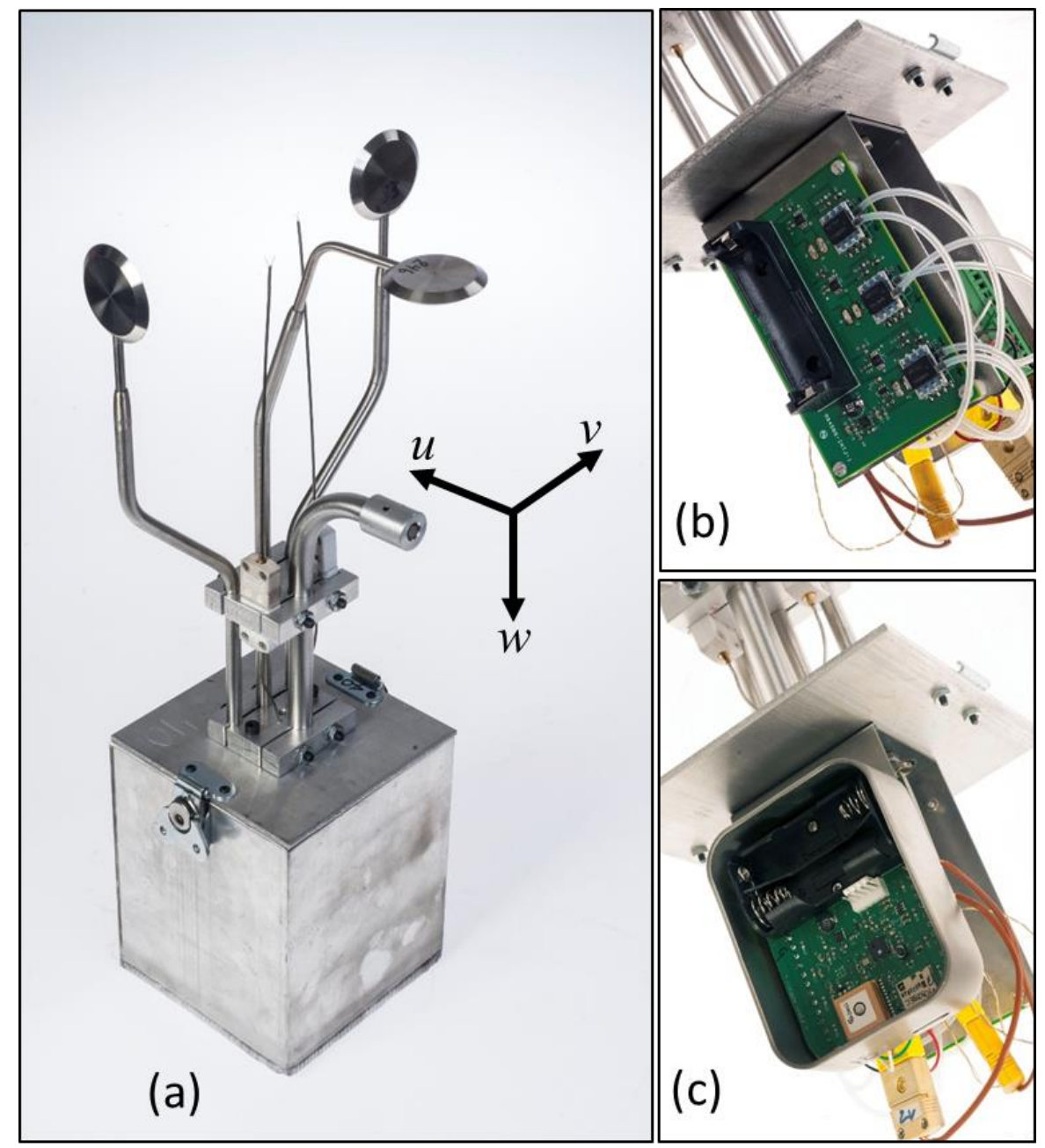

Figure 2 - (a) Fully assembled heat flux package showing disks of the anemometry system, thermocouples, radian heat flux gauge, and electronics enclosure; (b) Pressure signal conditioner; (c) Data logger. For a sense of scale, the heat flux package is $47 \mathrm{~cm}$ tall.

Disk anemometry works on the principle that the differential pressure measured on opposite faces of a disk is solely a function of the wind velocity and the angle the wind vector makes with the normal of the disk. Consider the disk schematic in Fig. 3 wherein the wind vector $\vec{u}$ is at angle $\alpha$ relative to the disk normal. The azimuthal angle $\phi$ is irrelevant to differential pressure measurement because of the rotational symmetry of the disk. Ideally, the differential pressure $\Delta p$ would vary strongly and linearly with both $\vec{u}$ and $\alpha$ so the methodology would be tolerant of small measurement inaccuracies.

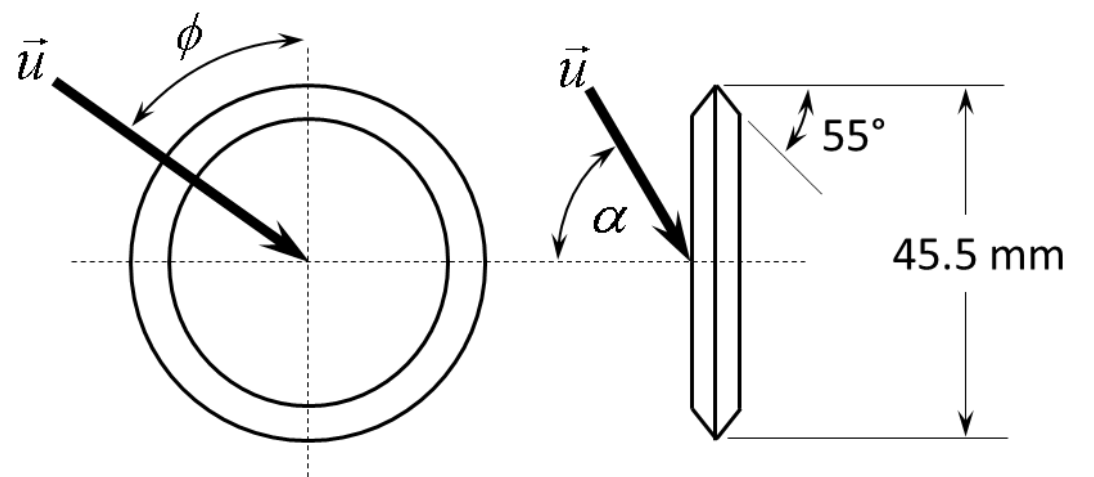

Figure 3 - Diagram of the front and side views of disks with some arbitrary wind vector. 
However, in practice $\Delta p$ is a weak function of $\vec{u}$ (or, more generally, Reynolds number $\mathrm{Re}$ ) and the relationship with $\alpha$ is nonlinear.

\section{Description of the Heat Flux Package}

\subsection{Heat Flux Package Design}

The heat flux package (Fig. 2a) is an instrument that is in ongoing development. Its purpose is to fulfil a need for acquiring the data needed to calculate the convective heating that fine fuels experience just ahead of a wildland fire front - namely, flow speed, flow direction, and gas temperature. The heat flux package also has the ability to measure radiant heat flux over a broad field of view.

The instrument contains three principle measurement capabilities: anemometry of local wind flows, thermometry of local gas temperature, and measurement of radiant heat flux. Here, we are concerned only with the first two since both wind speed, wind direction, and gas temperature are required for calculating convective heat transfer. Anemometry is accomplished with three disks that experience a differential pressure between the two faces of the respective disk that varies as a function of wind speed and incident angle relative to the disk faces. The differential pressure is measured by pressure transducers that communicate with the disk faces through internal plumbing connected to pressure taps on either face of the disk. Measurement of winds coming from any direction is made theoretically possible by the positioning of the disks in the three mutually orthogonal directions. The disk diameter $(44.5 \mathrm{~mm})$ and thickness $(6.1 \mathrm{~mm})$ were determined by scaling up the design in Green (Green et al. 2001) by a factor of 1.75 . The $55^{\circ}$ bevel on the disk edge as recommended by Green (Green and Rogak 1999) was maintained in our design. We decided to scale up the disk geometry to mitigate some of the disk manufacturing challenges.

The disks were machined with a CNC lathe by a local shop from 304 stainless steel round stock. The $1.588 \mathrm{~mm}(1 / 16 \mathrm{in}$.) holes required for internal pressure tubing proved to be the most challenging step - requiring careful attention to feeds and speeds to avoid breaking the diminutive drill bits. We plan to use 303 stainless steel, a more readily machinable alloy, for future versions.

The support tubes positioned the disks away from the electronics enclosure and also protected the small diameter pressure tubes from damage. Support tubes were made from seamless heavy-walled stainless steel tubing and bent into the design shape. Rather than

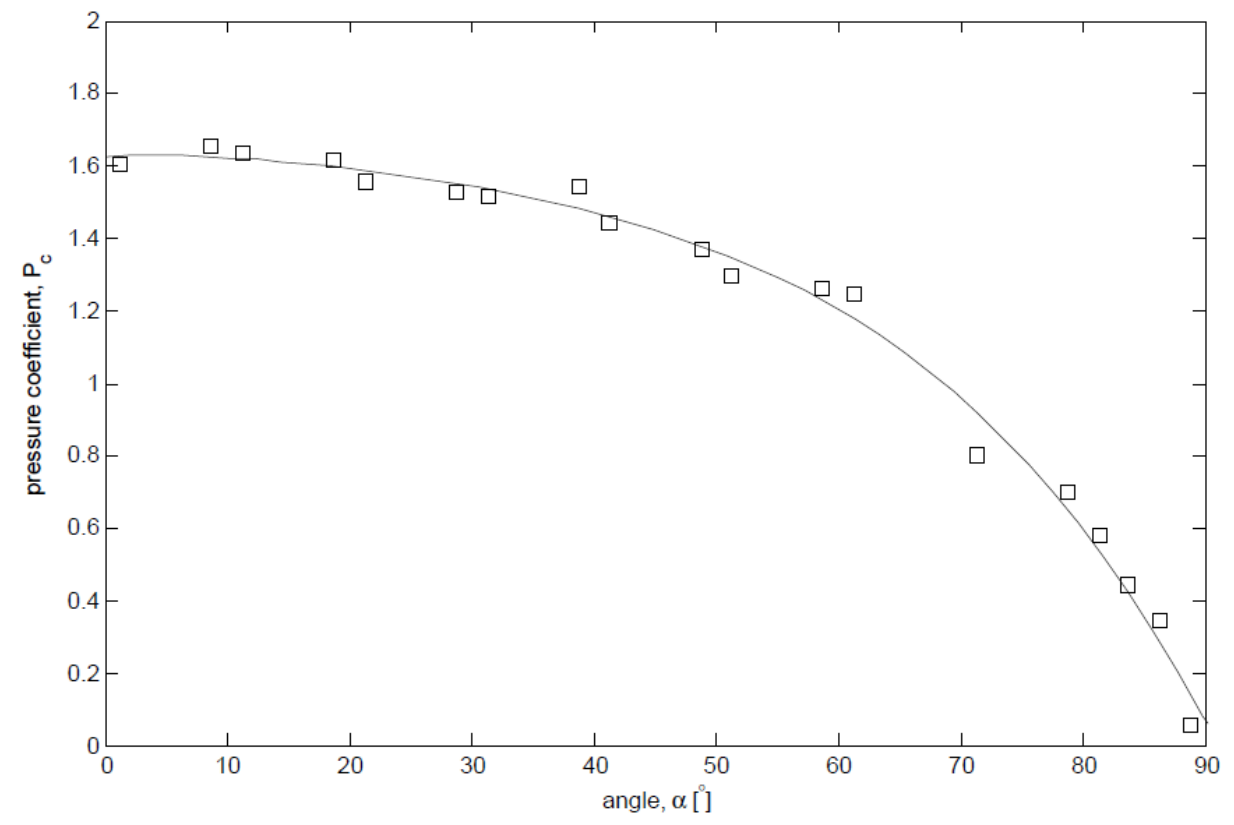

Figure 4 - Plot showing the sensitivity of pressure to angle. 
welding, the support tubes, pressure tubes, and disk were bonded together with high-temperature metallic adhesive (Durabond 954OD, Cotronics Corp.).

Local air and combustion gas temperature was measured by a pair of fine gauge thermocouples. The thermocouples consisted of a ceramic male connector, approximately $15 \mathrm{~cm}$ of stainless-steel-clad extension wire (Omega Engineering Omegacladi), and the actual thermocouple junctions were 50 micron welded junctions from the same vendor.

\subsection{Pressure Electronics and Data Logger}

The pressure gradient between one face of a disk relative to the opposite face was communicated to the electronics enclosure (Fig. 2a) by small diameter stainless steel tubing that was routed through the support tubes. Once inside the enclosure, the tubes were attached to three differential pressure transducers (Honeywell HSCDRRN001NDAA $5^{\mathrm{i}}$ ) which have a range of \pm 249 Pascal ( \pm 1 inch of water column). The pressure transducers were soldered to a signal conditioning circuit board (Fig. $2 \mathrm{~b}$ ) which converted the single-ended 3.3 volt output signal to a 2.5 volt differential signal that is compatible with the data logger. The pressure transducer signal conditioning circuit board was designed in-house and was powered by a single AA battery.

The three pressure transducers, two thermocouples, and two radiant heat flux gauge circuits constitute seven differential voltage signals. These data are recorded by a data logger (Fig 2c) that was also designed in-house for the heat flux package and other field-going wildland fire research instruments. The logger acquires data from eight, 24-bit differential channels at $50 \mathrm{~Hz}$ for up to 20 hours when powered by a pair of high-quality alkaline batteries. The internal clock is set from Global Positioning System (GPS) satellite signals so that multiple loggers can be synchronized prior to deployment on a fire. The acquired data is stored on a removable microSD card. The compact logger design fits within a $92 \times 73 \times 32 \mathrm{~mm}$ steel tin (including batteries).

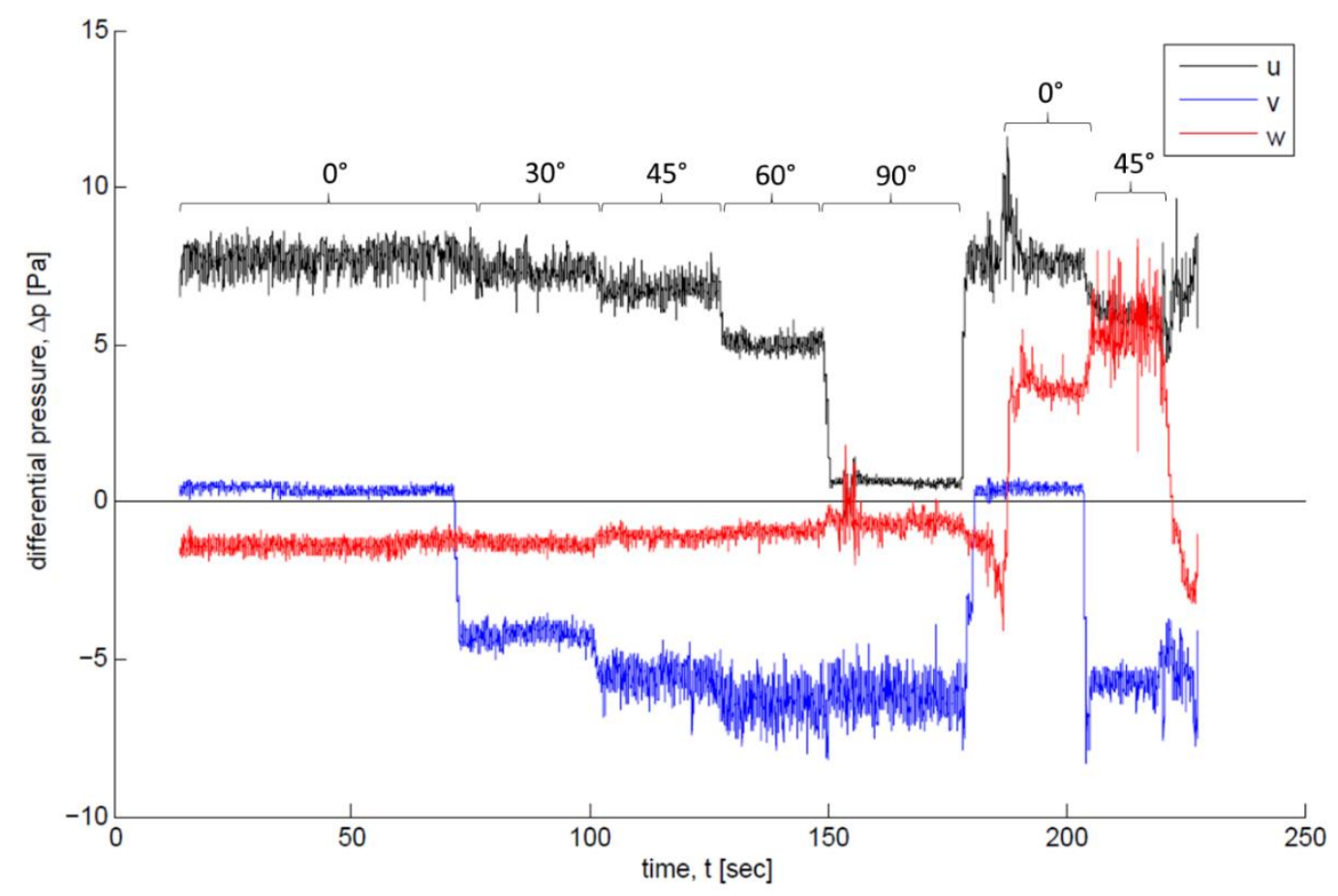

Figure 5 - Pressure traces from the three orthogonal components for a range of flow angles.

\subsection{Field Deployment of Heat Flux Package}

The heat flux packages are set up in the field with the disks approximately level with the height of the fuel. The heat flux packages are positioned vertically using a round bubble level. The azimuthal 
direction is determined by the wind direction expected at the time of ignition. A magnetic compass is used to ensure all the heat flux packages are pointed in the correct direction. ${ }^{1}$ Once all the heat flux packages are properly buried and oriented in a burn plot, the loggers are activated by inserting batteries. The loggers are given time to acquire signals from GPS satellites to synchronize their clocks, then the packages are closed up and thermocouples inserted into the plugs. There is no need to start logging immediately prior to ignition since the loggers can function all day. This method avoids the complication of triggering the logger to begin acquiring just as the fire approaches. Following the passing of the fire, the loggers are shut off and data cards collected.

\section{Results and Discussion}

Wind tunnel testing of the heat flux packages revealed aerodynamic properties of the anemometry system. This section contains results and interpretation of this testing, and plans for development moving forward.

Fig. 4 shows how pressure (in the form of pressure coefficient) varies as a function of angle $\alpha$ at $\mathrm{Re}=14000$, where the length scale is the $44.5 \mathrm{~mm}$ disk diameter. Between $0^{\circ}$ and approximately $60^{\circ}$ the relatively flat trend shows that pressure is a weak function of $\alpha$, while for angles $60^{\circ}$ to $90^{\circ}$ the dependence is stronger. The implications of this relationship are that small uncertainties in the measurement of pressure when the disk is at an angle of $0^{\circ}$ to $60^{\circ}$ to the wind will cause disproportionately large inaccuracies in the angle determined from the measured pressure. For flow angles beyond $60^{\circ}$, the trend is more favorable because the dependency is much stronger. The plot in Fig. 4 is representative of the pressure coefficient trend with angle for all Reynolds numbers tested (up to 45000). While this level of angular sensitivity is an improvement over bi-directional probes, it is not sufficient to ensure adequate tolerance of small inaccuracies of pressure measurement.

Fig. 5 shows other results from placing the heat flux package in the wind tunnel. The vertical axis shows differential pressure across the two faces of the respective disks. The signs of the pressures correspond to the $u, v, w$ axes illustrated in Fig. 2a. The numerical angles and brackets indicate the direction of the wind to which the heat flux package was subjected. For example, from 14 to 70 seconds, the heat flux package was positioned to face straight into the wind, generating a maximal signal in the $u$ component and nearly zero in the $v$ component. The heat flux package was tilted slightly backward to create a small negative $w$ component. The flow angle was systematically varied over the indicated angles from 17 to 180 seconds. From 180 to 220 seconds, the heat flux package was tilted forward approximately 25 degrees, creating a significant positive $w$ component. The Reynolds number with respect to the disk diameter is 10000 .

The plot in Fig. 5 demonstrates the difficulty in implementing the disk anemometry technique. Note that over the range of $0^{\circ}$ to $45^{\circ}$, there is little change in the pressure measured in the $u$ component. This range of angles corresponds to the region in the plot in Fig. 4 in which pressure has a weak dependence on angle. If angle is unknown (as it would be in a field deployment), it would be difficult to distinguish between, for example, wind coming from a bearing of $0^{\circ}$ or $20^{\circ}$. It is apparent that the differential pressure measured on the disks - as designed - does not have sufficient angular discrimination to be useful in the field. An improvement in disk design is warranted.

${ }^{1}$ Since the basic function of the disk anemometry system is to measure a three dimensional flowfield, the orientation of the heat flux packages would normally be irrelevant. However, the instrument is faced towards the expected fire front to ensure maximum converage by the radiant heat flux gauge acceptance angle $\left(\sim 110^{\circ}\right)$. 
A further source of error arises from the physics of the problem. Consider the pitot tube equation: $u=\left(2 \Delta p \rho^{-1}\right)^{0.5}$. The quadratic relationship between $u$ and $\Delta p$ means that when $\Delta p$ is near zero (i.e., velocity near zero), small inaccuracies in the measurement of $\Delta p$ results in disproportionately large inaccuracies in the calculated velocity (McCaffrey and Heskestad 1976). This effect compounds error that arises from angular insensitivity.

Wind tunnel testing has shown that there are significant limitations to using the disks for anemometry as they are presently designed. The weak angular sensitivity for angles over the range $0^{\circ}$ to approximately $60^{\circ}$ means that inaccuracy in pressure measurement can be magnified when calculating the corresponding velocity. Green and Rogak (1999) noted that improving the design of the disk requires an understanding of the boundary layer attachment and separation that occurs on the surface of the disk at relevant Reynolds numbers. To that end, we plan to carry out CFD simulations of various styles of disk designs. We will seek a design that is more sensitive to changes in angle so that it is more tolerant of small inaccuracies in pressure measurement.

\section{Conclusion}

We report on the ongoing development of a new style of instrument package to measure threedimensional flow speed and direction in wildland fires. The all-metal construction and lack of moving parts enables the instrument to survive immersion in flames for measurements in all fuel types. Disk style probes are used instead of the more common bi-directional probe to improve angle sensitivity of pressure measurement. Improved angular discrimination will permit calculation of fully three dimensional flow direction in addition to flow speed. An instrument package incorporating the disk anemometry system was developed and underwent preliminary testing. While the disk-style probe shows some improvement in angular sensitivity over a bi-directional probe, further improvement will result in greater tolerance in small pressure measurement inaccuracies.

\section{Acknowledgements}

Significant help in design, production, and assembly of heat flux packages was provided by our technical staff: Randy Pryhorocki, Josh Deering, Chelsea Phillips, Andrew Gorris, and Jon Bergroos. This work was supported by U. S. Forest Service Research and the National Fire Decision Support Center.

\section{References}

Finney, MA, Cohen, JD, Forthofer, JM, McAllister, SS, Gollner, MJ, Gorham, DJ, Saito, K, Akafuah, NK, Adam, BA, English, JD (2015) Role of buoyant flame dynamics in wildfire spread. Proceedings of the National Academy of Sciences 112, 9833-9838.

Finney, MA, Cohen, JD, McAllister, SS, Jolly, WM (2013) On the need for a theory of wildland fire spread. International Journal of Wildland Fire 22, 25-36.

Green, SI, Ostafichuk, P, Rogak, SN (2001) Measurement of three-dimensional unsteady flows using an inexpensive multiple disk probe. Journal of Atmospheric and Oceanic Technology 18, 883-891.

Green, SI, Rogak, SN (1999) A multiple disk probe for inexpensive and robust velocimetry. Journal of Fluids Engineering 121, 446-449.

Holman, JP, 1997. Heat transfer. McGraw-Hill Inc,

McCaffrey, B, Heskestad, G (1976) A robust bidirectional low-velocity probe for flame and fire application. Combustion and Flame 26, 125-127. 